\title{
Acoustical cues to the reconstruction of missing words in speech perception
}

\author{
WILLIAM E. COOPER, NANCY TYE-MURRAY, and STEPHEN J. EADY \\ University of lowa, Iowa City, lowa
}

\begin{abstract}
A series of experiments was conducted to examine whether listeners could utilize subtle acoustical cues in reconstructing words that were missing from the speech signal. Preliminary tests revealed that listeners can make use of semantic context in such reconstruction, analogous to earlier results in reading. In Experiment 1, listeners were able to use intonational cues at the beginning of a string to detect whether or not a sentence-initial word had been missing. In Experiments 2 and 3, listeners utilized coarticulatory cues for palatalization in sentence-internal locations to guide their lexical selection of reconstructed words. In Experiment 4, listeners were influenced in lexical selection by the duration of a silent interval that had replaced the missing word. Taken together, the results indicate that listeners can utilize the acoustical fine structure of speech to both detect the occurrence of a missing word and guide its lexical reconstruction.
\end{abstract}

During ordinary listening, an individual might miss part or all of a word or phrase because of background noise or momentary lapse of attention. Introspection suggests that such "misses" are commonplace during all but the most intent conversations. Yet, very little is known about the conditions under which listeners detect misses, the conditions under which they attempt to reconstruct the missing information, the kinds of contextual information that might help to guide reconstruction, and how the processing of such information might differ depending on the factor(s) that contributed originally to the loss.

Previous research has shown that normal listeners can utilize contextual cues to aid in reconstructing missed speech sounds. In phoneme restoration studies, a target phoneme is deleted from the speech signals and typically replaced by a noise source. Results with this paradigm indicate that listeners are influenced by semantic and acoustical information in restoring missing speech sounds (e.g., Samuel, 1981a, 1981b; Warren, 1970).

The term "restoration" has commonly been used to refer to a perceptual illusion in which listeners hear a missing phoneme without detecting the site of this miss. In extending such work to missing word units, we shall use a more general term, "reconstruction," to refer not only to automatic restoration but also to a more conscious type of process in which the listener does detect the site of a miss and attempts to identify the missed word. A detailed

This work was supported by NIH Grant NS 20071. Portions of this research were presented at the 25th Meeting of the Psychonomic Society, San Antonio, Texas, November 8, 1984. We are grateful to Lori Nelson and Mary McNulty for assistance in running subjects, to Patricia Colsher for help with statistical analyses, and to Bryant Julstrom for computer programming. We also thank Arthur G. Samuel and Robert G. Crowder for helpful comments.

The authors' mailing address is: Department of Psychology, Spence Laboratories of Psychology, University of Iowa, Iowa City, IA 52242. examination of the conditions under which word reconstruction is carried out as a conscious process is treated separately (Cooper, Tye-Murray, \& Nelson, 1985). The present effort is focused instead on identifying basic acoustical cues that might influence listeners' reconstruction of missing words, irrespective of whether this process is accomplished consciously.

\section{PRELIMINARY EXPERIMENTATION}

In this preliminary experiment, the general utility of the experimental method was assessed by testing word reconstruction of verbs in contexts providing high versus low predictability. In many English sentences, a verb is highly predictable from context, as in a sentence like "John ( ) the book on the table," where a verb like "put" is a plausible candidate. We compared sentences containing verbs of high versus low predictabilty in both visual and auditory modes to determine the extent to which subjects use semantic context in reconstruction. Mere demonstration of a contextual effect is amply foreshadowed by available literature on reading (e.g., Stanovich \& West, 1981) as well as speech perception (e.g., Morton \& Long, 1976), but we wanted to ascertain the validity of our general methodology, and, in addition, we anticipated that the study of error patterns might provide some new information.

The subjects were 112 undergraduates at the University of Iowa. Twenty sentence pairs were constructed. Each sentence pair contained a matched key word but differed in the extent to which surrounding context could potentially aid in key-word restoration. Some representative sentence pairs appear below:

1. a. After the fight, students threw rocks at the police.

b. After school Kerry threw books and papers on his desk. 
2. a. In order to give the house more privacy, I planted bushes along the sidewalk.

b. In order to give us all a change of pace, I planted corn instead of broccoli.

As these examples show, the key words were verbs located near the middle of the sentences. In the " $a$ " sentence of each pair, the key word is highly predictable from context according to intuition, whereas in the corresponding " $b$ " sentence the key word is less predictable. This intuitive contrast is verified below in the results for the written version of the test.

In addition to the 20 pairs of test sentences, 60 filler sentences were constructed. Like the test sentences, each filler sentence contained one key word that was to be deleted, but in the fillers the location and grammatical category of the key word was varied for the purpose of camouflaging both the relatively constant key-word location and the constant grammatical category type of the key words in the test sentences.

The test sentences and filler sentences were ordered pseudorandomly and presented to subjects in either a visual or auditory mode. Half of the 112 subjects were administered the visual test, and half were administered the auditory test. For the visual test, the sentences were presented in typewritten form on sheets of paper. The key word in each sentence was replaced by a blank space of constant length. The subjects' task was to read each sentence and to fill in the blank space by writing a word that was appropriate for the given context. For the auditory mode of presentation, the stimulus sentences were first recorded on audio tape by a female speaker. The key words were then mechanically deleted from the audio signal by re-recording the stimulus with a two-channeled tape recorder, replacing the word with a silent interval of equal duration (all subsequent experiments employed a computerized electronic editing procedure, as described below). The resulting stimulus sentences were presented binaurally over headphones, and the subjects' task was to listen to each sentence and to write down the word that they thought had been deleted.

A silent interval was chosen to replace the deleted word for the sake of technical simplicity. However, in realworld contexts, words or portions thereof are ordinarily masked by environmental noises. Moreover, a silent interval can be misinterpreted as a pause, a possibility addressed directly in related experimental work with extended listening contexts (Cooper, Tye-Murray, \& Nelson, 1985). In recent experiments, we have found that replacing the deleted word with a natural chair-scrape noise, embedded in the general context of low-intensity classroom noise, serves more adequately to simulate a natural listening circumstance. However, the silent interval was utilized here as the primary replacement for a deleted word and should provide a useful basis for comparison with further work using more natural masking.

As anticipated, the results of these tests showed that the percentage of matches between the subjects' responses and the word that had been deleted was significantly greater in predictable than in unpredictable contexts. This effect was observed in each of the visual $(72.5 \%$ vs. $4.6 \%$ for the predictable and unpredictable contexts, respectively) and auditory (63.8\% vs. $3.4 \%$ ) modes of presentation $(p<.05)$. However, the results of error analyses indicated that, in the auditory mode, listeners restored words in a manner that differed in certain respects from the type of word reconstruction that accompanies the visual mode, in which the location of the deleted word is more clearly signaled and in which the subject can take advantage of repeated scanning in typical circumstances (in artificial circumstances, rapid serial visual presentation would provide a visual analogue to the typical auditory case). Thus, the reconstruction of words in the auditory mode exhibits certain characteristics that are distinctively associated with the normal operation of this mode. Put another way, reconstruction as examined here is not merely a form of crossword puzzle exercise, in which only semantic and syntactic information is utilized. Results showing the relevance of acoustic cues to word reconstruction, to be presented in the main experiments, further substantiate this claim.

The target-reconstruction mismatches could be classified into systematic categories for the most part, including, for example, errors involving the reconstruction of a word that already has appeared nearby in the string, as in examples $1 \mathrm{a}$ and $1 \mathrm{~b}$ below (a possible problem in reality monitoring; see Johnson \& Raye, 1981), and errors involving the report of a word locally appropriate in producing a semantically appropriate noun phrase, but yielding a verbless, ungrammatical sentence, as in examples Ic and $1 \mathrm{~d}$ below.

1. a. Our son (son) jewelry and got arrested. target $=$ stole

b. I'll (shelves) shelves for the books in my office at work. target = buy

c. As the holiday approached, I (many) blankets for the presents. target $=$ bought

d. I'll (new) shelves for the books in my office at work. target $=$ buy

We have catalogued errors from related experiments to provide information about such issues as the extent to which distant versus nearby contextual information influences the choice of a reconstructed word. In addition, we have included a full-sentence report procedure to examine the degree to which listeners correctly recall the words actually present in the signal (Cooper, Tye-Murray, \& Nelson, 1985). The results of such work indicate that listeners are generally quite accurate $(95 \%)$ in recalling the words that appeared in the original string.

In a second preliminary test, we examined whether the position of the missing word influenced reconstruction. Three versions each of 10 base sentences were constructed, in which a key word appeared near the begin- 
ning, middle, or end of the string, as in the following examples:

2. a. The farmer plowed his fields in the spring before planting the corn.

b. In the spring the farmer plowed his fields before planting the corn.

c. Before planting corn in the spring the farmer plowed his fields.

The results for 19 listeners showed no significant differences in the percentage of target-reconstruction matches across the three positions, although a trend toward decreasing matches was observed from beginning to end (percent matches $=61.6 \%, 56.3 \%$, and $50.0 \%$ for beginning, middle, and end, respectively). Thus, although no major effect was obtained, the appearance of this trend prompted us to control for position in the main experiments. In these experiments, we began to explore the extent to which listeners can utilize subtle acoustical cues for both detecting the occurrence of missing words (Experiment 1) and guiding the choice of lexical reconstruction (Experiments 2-4).

\section{EXPERIMENT 1}

One of the most likely circumstances for listeners to miss words in natural listening occurs at the initiation of an utterance, and comprehension can be seriously impaired as a consequence. For example, if a speaker says, "No county courthouses are open on Saturday," and the listener does not process the first word, the listener may decode the utterance with a meaning opposite to the one intended.

This experiment was designed to examine the possible role of syntactic and acoustic cues for helping listeners to recognize when a sentence-initial word is missing. Secondarily, we also wanted to determine how accurately listeners can guess the identity of such missed words.

\section{Method}

Subjects. Seventy-two undergraduates participated in this experiment, as part of a course requirement in Elementary Psychology at the University of Iowa.

Sentence materials. Two groups of base sentences were designed for this study. In each sentence, the first word could be optionally deleted to produce a change in meaning. In one group of seven base sentences, the optional first word was the negative adjective " $n$ o"; various descriptive adjectives appeared at the beginnings of the second group of eight base sentences. Examples appear below.

From Group 1:

3. No doctors are seeing patients in the clinic tomorrow.

4. No county courthouses are open on Saturday mornings.

5. No pets are permitted in our apartment complex.

From Group 2:

6. White corn is extra sweet this year.

7. Russian troops are now on red alert.

8. My boys like to play baseball.
Two versions of each of the 15 base sentences were recorded by a male speaker of American English. One version corresponded to the sentences as presented above; the second version omitted the sentence-initial word. A third version of each base sentence was created by electronically deleting the sentence-initial word from the first version. For this electronic manipulation, the sentences were digitized at $10 \mathrm{kHz}$ and displayed oscillographically on a Lexidata 2400 high-resolution graphics terminal from a PDP-11/23 computer. The visual display of the initial portion of the sentence was expanded on the terminal screen to facilitate identification of the end of the key word. When the key word had been demarcated, it was electronically deleted and replaced with an equal interval of silence. In some instances, the endpoint of the target word was difficult to pinpoint due to the effects of coarticulation, and in these instances a trial and error procedure was used to ensure that all acoustic information pertaining to the target word had been deleted, on the basis of the judgments of two phoneticians who listened to the altered sentences.

Electronic deletion of this sort is optimized when the word following the key word begins with a voiceless consonant or a voiced stop consonant, since it is relatively easy to identify the onset of these speech sounds on a waveform display. In 10 of the 15 base sentences used in this experiment, the word following the key word begins with a voiceless consonant $(/ \mathrm{p}, \mathrm{t}, \mathrm{k}, \mathrm{s}, \mathrm{f} /)$. Three other sentences have second words beginning with voiced stops $(/ \mathrm{d}, \mathrm{b}, \mathrm{g} /)$.

Unlike the preliminary experiments, the deletion process itself is strategic in this experiment because any waveform anomalies resulting from this process would provide the subjects with an extraneous cue relevant to the response of whether or not a deletion had occurred. For this reason, all stimuli were digitized and electronically edited. For the first two versions of each sentence (in which no words were to be deleted), all ambient noise preceding the first word was electronically eliminated. For the third version, the first word of the sentence and all noise preceding the first word were eliminated. In all sentences, the beginning of the edited speech signal was made to correspond with a zero-crossing on the waveform, in order to prevent a sudden amplitude transition that might give evidence of the electronic manipulation. Illustrative waveforms for speech signals produced by this editing procedure are displayed in Figure 1. Waveforms for the beginning of Versions 1, 2, and 3 appear from top to bottom for the sentence "No pottery can be sold by artists without a sales permit." The top frame shows the phrase "no pottery" at the beginning of Version 1 . The middle and bottom frames show the word "pottery" at the beginning of Versions 2 and 3. The onsets of the first vowel in "pottery" are aligned for all three versions to illustrate differences among the waveforms. Subsequent acoustical analysis of the resulting stimulus materials (see later) confirmed that the procedure was successful in avoiding transients while still retaining the natural acoustic attributes of the neighboring nondeleted word.

Procedures. The subjects were tested in groups of eight in an audio testing room with individual listening stations. The subjects listened over headphones at a comfortable listening level to the output of a reel-to-reel tape recorder. Prior to this experiment, the subjects had participated in a related experiment involving missed words in various locations and were thus familiar with the task. Each group of subjects was presented 15 sentences containing one version of each base sentence. The subjects heard seven sentences of one version, five of another, and three of the remaining version. Three separate subject groups were tested so that each version of each base sentence was presented an equal number of times. In each test, the ordering of the sentences was pseudorandomized.

The subjects were told that approximately one-third of the sentences had originally contained a sentence-initial word that was now missing. The subjects were told to draw a line on the answer sheet for sentences that were judged to have had no words deleted. They were told to guess the identity of the deleted words in the remaining sentences by writing their responses on the answer sheet. 

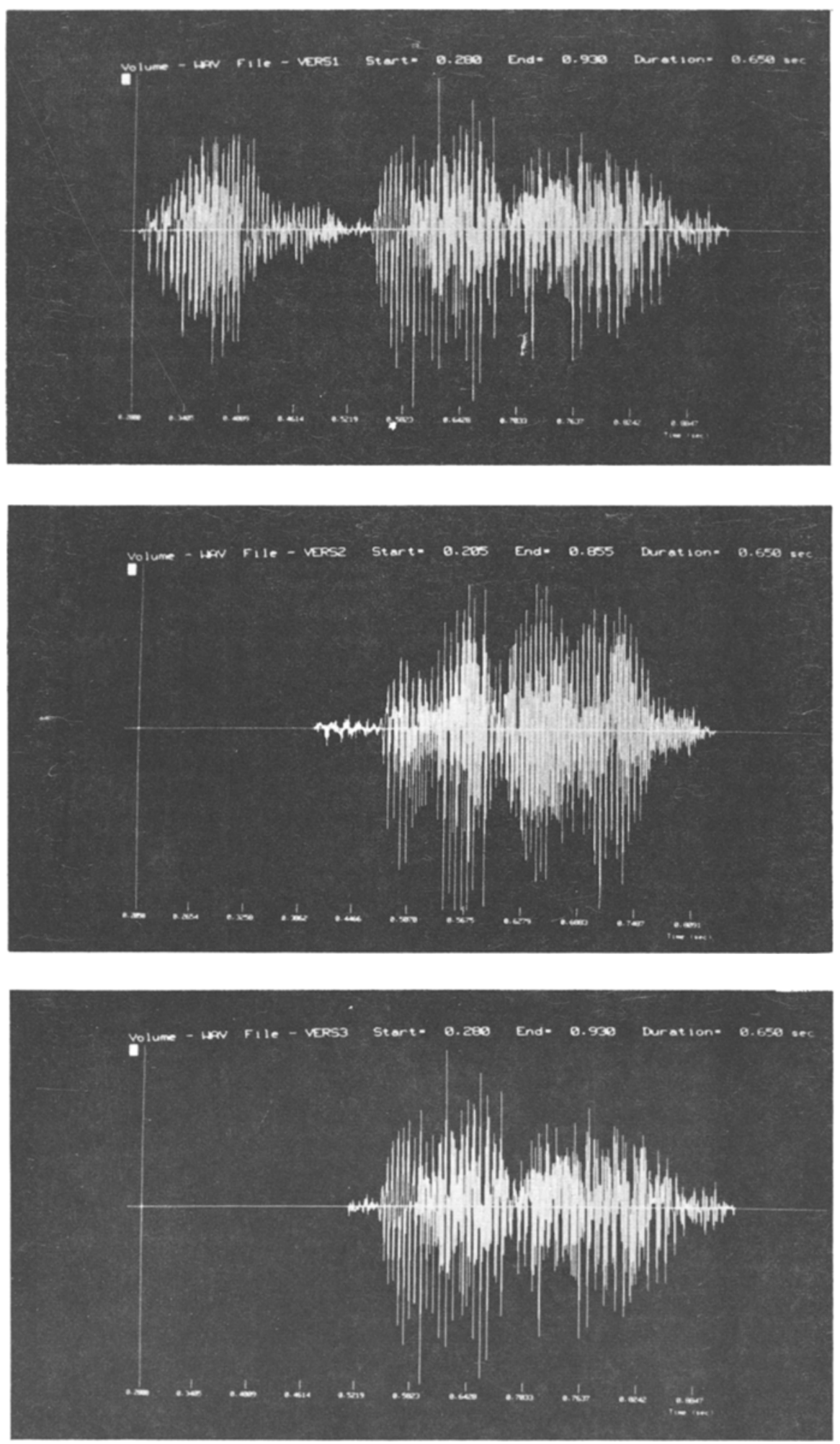

Figure 1. Comparison of waveforms for the beginning of Versions 1-3 for the sentence "No pottery can be sold by artists without a sales permit." The top frame shows the phrase "No pottery" at the beginning of Version 1 . The middle and bottom frames show the word "pottery" at the beginning of Versions 2 and 3. The onsets of the first vowel in "pottery" are aligned for all three versions to illustrate differences among the waveforms, as discussed in the text. 


\section{Results and Discussion}

The results of this experiment are presented in Table 1, which shows the total number of "no-deletion" responses as a function of sentence version for each of the two sentence sets. As this table reveals, there is a systematic decrease in the number of "no-deletion" responses as we proceed from Versions 1 to 3 . This trend is evident for both sentence sets.

The Wilcoxon rank sum test was used to evaluate the response difference between versions. The results of this test show a significant difference among the three versions for the initial negative sentences, with Version 1 sentences eliciting a significantly greater number of "no-deletion" responses than did Version 2 sentences $(p<.01)$ and Version 2 sentences eliciting a significantly greater number than did Version 3 sentences $(\mathrm{p}<.05)$. Likewise, for the sentences with initial adjectives, the Version 1 sentences elicited a significantly greater number of "no-deletion" responses than did the Version 2 sentences $(p<.05)$, and the Version 2 sentences elicited a significantly greater number of "no-deletion" responses than did the Version 3 sentences $(p<.01)$.

To explain these results, we suggest that the listeners take into account both structural and acoustic attributes of the stimulus sentences. In the first two versions, which actually contained no deletion site, listeners responded correctly more often in Version 1 sentences. Since Versions 1 and 2 were identical except for the extra negative or adjective at the beginning of Version 1, the greater accuracy of listeners in Version 1 can be attributed to the fact that, on structural grounds, it is unlikely that yet another modifier would have been deleted from the beginning of the string. For example, in the sentence "No pets are allowed in our apartment complex," relatively few modifiers could be plausibly added to the beginning of the string (e.g., "absolutely"), whereas in the corresponding Version 2 sentence, beginning with the noun "pets," a range of modifiers is plausible.

Versions 2 and 3 were structurally identical except that Version 3 was derived by electronically deleting a sentence-initial word. Thus, the correct response for Version 2 would be "no deletion," whereas the correct response for Version 3 would involve restoration of a missing first word. Version 2 elicited a significantly greater number of "no-deletion" responses than did Version 3 for both sentence groups. This difference in "nodeletion" responses can probably be attributed to the fact that, in Version 2, the acoustic/articulatory cues at the initiation of the sentences were consistent with an intact utterance, whereas in Version 3 they were not.

To investigate the acoustic attributes that might be responsible here, we conducted a computerized acoustical analysis, comparing attributes in the first words of Version 2 and Version 3 sentences. Measurements were made for the peak in fundamental frequency (F0), the shape of the F0 contour (e.g., rising, falling, plateau), total word duration, duration of the aspiration interval for words beginning with voiceless stops, and duration of frication for words beginning with fricatives. In the case of the two F0 attributes, prior work has shown some potentially relevant differences between the first and second words of sentences that might serve as cues here for detecting the deletions in Version 3 (e.g., Cooper \& Sorensen, 1981; Lieberman, 1967; Maeda, 1976; Vaissiére, 1980).

Of the acoustical measures, the two involving F0 consistently distinguished the first words of the two versions. In particular, the first word of Version 2, involving no deletion, was accompanied by a relatively high peak F0 (mean $=193 \mathrm{~Hz}$ ) and a generally rising F0 contour throughout the word. In contrast, the first word of Version 3 was accompanied by a significantly lower peak (mean $=163 \mathrm{~Hz} ; \mathrm{p}<.01$ ) and a generally falling contour. No consistent differences were found among the other acoustic attributes in comparing the two versions.

We believe that the difference in the F0 contours of the sentence-initial words contributed to listeners' decisions about word deletions. This hypothesis is based on a recent acoustical study (Cooper, Eady, \& Mueller, 1985), which shows that declarative sentences of this type almost always have a rising F0 contour on the first word or syllable. A falling contour at this location is possible, but is invariably associated with emphatic or contrastive stress on the word in question. Since the other acoustical cues in these sentences were not consistent with emphatic stress (i.e., increased word duration and a low, flattened F0 contour following an initial emphasized word), the falling F0 contour on the first word in Version 3 would be perceived as unnatural and would lead to more deletion responses.

Table 1

Number of Responses by Construction Type in Experiment 1

\begin{tabular}{|c|c|c|c|c|c|c|}
\hline \multirow[b]{3}{*}{ Response Type } & \multicolumn{3}{|c|}{ Group 1 Sentences (Initial Negatives) } & \multicolumn{3}{|c|}{ Group 2 Sentences (Initial Adjectives) } \\
\hline & \multicolumn{3}{|c|}{ Version } & \multicolumn{3}{|c|}{ Version } \\
\hline & $1(\mathrm{~N}=168)$ & $2(\mathrm{~N}=168)$ & $3(N=168)$ & $1(N=192)$ & $2(\mathrm{~N}=192)$ & $3(\mathrm{~N}=192)$ \\
\hline "No deletion" responses & $\begin{array}{c}164 \\
(97.6 \%)\end{array}$ & $\begin{array}{c}130 \\
(77.4 \%)\end{array}$ & $\begin{array}{c}78 \\
(46.4 \%)\end{array}$ & $\begin{array}{c}151 \\
(78.6 \%)\end{array}$ & $\begin{array}{c}112 \\
(58.3 \%)\end{array}$ & $\begin{array}{c}35 \\
(18.2 \%)\end{array}$ \\
\hline Target matches & NA & $\begin{array}{c}11 \\
(6.5 \%)\end{array}$ & $\begin{array}{c}17 \\
(10.1 \%)\end{array}$ & NA & 0 & $\begin{array}{c}2 \\
(1.0 \%)\end{array}$ \\
\hline $\begin{array}{l}\text { Semantically inappropriate } \\
\text { responses }\end{array}$ & 0 & $\begin{array}{c}1 \\
(0.6 \%)\end{array}$ & $\begin{array}{c}1 \\
(0.6 \%)\end{array}$ & 0 & $\begin{array}{l}1 \\
(0.5 \%)\end{array}$ & $\begin{array}{l}2 \\
(1.0 \%)\end{array}$ \\
\hline $\begin{array}{l}\text { Syntactically inappropriate } \\
\text { responses }\end{array}$ & $\begin{array}{l}2 \\
(1.2 \%)\end{array}$ & $\begin{array}{c}1 \\
(0.6 \%)\end{array}$ & $\begin{array}{c}7 \\
(4.2 \%)\end{array}$ & $\stackrel{2}{2}$ & $\begin{array}{c}1 \\
(0.5 \%)\end{array}$ & $\begin{array}{l}4 \\
(2.1 \%)\end{array}$ \\
\hline
\end{tabular}


Although other acoustic parameters (e.g., amplitude) might well also play a role here, the peak and contour of the speaker's fundamental frequency seem to provide listeners with important information for detecting word deletions.

In this experiment, listeners' restorations seldom matched the deleted target word (approximately $5 \%$ overall), underscoring the importance of semantic cues, which were present in the first preliminary experiment but generally absent here. In many cases, plausible restorations yielded a meaning that differed drastically from that of the target. For example, restorations for the missing negative in Version 3 of the sentence "No formal pictures were taken during the centennial celebration last year" included "many," "the," "numerous," "several," and "some," but did not include "no" or related words.

The results for Version 3 can be accounted for by two general types of processes, which involve either contextual cues or an internal matching procedure. The major difference between the contextual and matching alternatives is that the former relies on evaluation of material neighboring the key site, which involves expectancies and overall rhythmic considerations of the sentence. On the other hand, the matching process relies on a more localized attempt to compare the signal at the key location with an internalized representation thereof.

Regarding the contextual alternative, Cutler (1976), for example, has demonstrated that listeners use the suprasegmental cues of an utterance to anticipate stressed syllables. Her findings indicate that the presence of a stressed syllable is implicitly represented in preceding context. In a similar vein, our findings suggest that listeners can utilize subtle intonational cues provided by following context to detect a missing sentence-initial word. Perhaps listeners notice the missing first word because the remaining F0 contour does not have the initial high peak characteristic of an intact sentence contour (e.g., Cooper \& Sorensen, 1981) and/or because the original temporal structure of the utterance's stressed and unstressed syllables is altered (e.g., Martin, 1972).

Alternatively, it is possible that the listener detects the deletion of a sentence-initial word by a matching process, whereby the listener tries to match intonational attributes of the first word in the signal to an internalized representation of ordinary attributes common to sentence-initial words. When the properties do not match, the listener assumes that a sentence-initial word has been deleted, according to this possibility.

\section{EXPERIMENT 2}

In this experiment, we examined the influence of acoustical cues on word reconstruction in sentence-internal locations where the choice of the reconstructed word was heavily constrained by context, unlike Experiment 1 . In the previous experiment, no segmental cues to the missing word were retained in the signal. Yet, it is possible that in ordinary circumstances listeners bother to try to reconstruct a missing word only if some segmental information is intact. In this experiment, we began to explore the possible influence of a segmental cue to reconstruction, involving a rule of cross-word phonological conditioning.

Palatalization is a rule that operates to convert an alveolar stop consonant $(/ \mathrm{d} /$ or $/ \mathrm{t} /)$ to a palatal affricate $(/ \mathrm{j} /$ or $/ \bar{c} /$ ) in the environment of a following glide $/ y /$. For example, "did you" is converted to /dIj(y)u/ (e.g., Cooper, Egido, \& Paccia, 1978; Oshika, Zue, Weeks, Neu, \& Aurbach, 1975). Important for present purposes is the fact that this rule is triggered across word boundaries only by the presence of a word-final $/ \mathrm{d} /$ or $/ \mathrm{t} /$; any other word-final phoneme prohibits palatalization. In this experiment, we wanted to determine whether listeners' reconstruction of a word would be influenced by the operation of palatalization prior to the word's deletion from the speech signal. For example, when a missing word is immediately preceded by the / $\mathbf{d l j} /$ form of "did," will listeners be more likely to reconstruct the missing word as "you" rather than "he," since the former, but not the latter, permits palatalization? Despite the likelihood that our listeners are not explicitly aware of the palatalization rule, do they nonetheless take the rule into account when attempting word reconstruction, or do listeners overlook such a subtle aspect of the acoustic signal in making their choices?

\section{Method}

Subjects. Thirty-eight University of Iowa undergraduates, none of whom had participated in earlier word reconstruction tests, served in partial fulfillment of a course requirement in Elementary Psychology. The subjects had the same qualifications as those who had served previously.

Sentence materials. Eight sentence pairs were constructed for use in this experiment. Two versions of each sentence were produced, involving a target word that either permitted or prohibited cross-word palatalization, as shown below:

9. a. Why did you/she put the book on the living room chair?

b. The baseball hit you/me between the eyes.

c. I knew that Paula had used/bought canned peas instead of fresh.

d. John had used/put too much salt in his casserole.

e. I told your/my father about the new restaurant downtown.

f. My uncle had an operation last year/month and now he is in the hospital again.

g. When I told her my age, the woman said, "You are not young/old enough to qualify for a discount."

h. I asked your/my brother if he would help us wash the car.

Procedures. A male phonetician read each version of the sentences for recording, producing palatalization at the key site for the versions in which the key word began with $/ y /$. Another phonetician listened to the productions and confirmed that the key word was palatalized in the appropriate version. The target words were then deleted and replaced with silence using the computerized editing procedure described previously. For the nonpalatalized version of each sentence, the entire target word was deleted and replaced with an equal interval of silence. For the palatalized version, only the portion of the key word following the palatal affricate was deleted and replaced with silence. The boundary between the affricate and the following vowel was defined to be the end of frication for the 
Table 2

Number of Responses by Reconstruction Type

in Experiment 2

\begin{tabular}{lcccc}
\hline & \multicolumn{3}{c}{ Sentence Version } \\
\cline { 2 - 5 } & Palatalized & $\%^{*}$ & Nonpalatalized & $\% *$ \\
\hline Responses beginning with $/ \mathrm{y} /, / \mathrm{j} /$, or $/ \breve{\mathrm{c}} /$ & 73 & 48.0 & 22 & 14.5 \\
Palatalizable target word & 38 & 25.0 & 22 & 14.5 \\
Nonpalatalizable target word & 71 & 46.7 & 82 & 53.9 \\
\hline *Percentage of the total number of responses. & & &
\end{tabular}

*Percentage of the total number of responses.

affricate. It was usually quite easy to locate this point on the computerized waveform display and to delete the portion of the word that followed. Identification of the phoneme boundary was aided by interactive listening to the segments on both sides of the boundary.

A pilot test with 19 subjects was conducted to ascertain word reconstruction responses for a written version of the sentence materials. The results indicated that both target words were plausible candidates for reconstruction in these sentences. In the main experiment, listeners were tested using the same procedure as in previous experiments. The subjects were divided into two groups of 19, with each group hearing one version of each sentence and an equal number of palatalized and nonpalatalized versions.

\section{Results and Discussion}

The results are presented in Table 2. The responses were categorized in terms of words that are compatible with palatalization (i.e., words beginning in $/ y /, / \mathrm{j} /$ or $/ \check{c} /$ ) and in terms of target matches. An analysis of variance revealed that significantly more responses beginning with phonemes compatible with palatalization were elicited for the palatalized versions of the sentences than for the nonpalatalized versions $[F(1,37)=27.0, p<.005]$. Likewise, examination of the number of actual target (i.e., original keyword) responses in Table 2 indicates that subjects were more likely to respond with the palatalizable target word when hearing the palatalized sentence version than when hearing the nonpalatalized version. Taken together, these results indicate that listeners possess implicit linguistic knowledge of the coarticulatory rule of palatalization and that they utilize such knowledge in selecting lexical items during word reconstruction.

\section{EXPERIMENT 3}

To further explore the influence of phonological structure on the reconstruction process, we conducted an experiment representing the converse of the previous design, in which the first word in the palatalization context was deleted. With this test, we provided a comparison of the effects of palatalization at the end versus at the beginning of a word.

\section{Method}

Subjects. Forty-eight undergraduates at the University of Iowa, none of whom had served previously, participated in this experiment. The subjects had the same qualifications as those who had served previously.

Sentence materials. Ten base sentences were constructed for use in this experiment. Two versions of each sentence were produced; these involved a target word that either permitted or prohibited crossword palatalization, as shown below:

10. a. "Why did/do you get arrested so often?" the interviewer asked the prisoner.

b. What did/do your parents think about your joining the Marine Corps?

c. Since no one respects that reporter, his slanderous words will not hurt/harm your reputation.

d. Why did/do your children go to a private school in Illinois?

e. John said that you bought/buy your peanut butter at a health food store for five dollars a jar.

f. Aunt Frances made/makes your mustard using an old recipe from my grandmother.

g. You are lucky that your parents paid/pay your bills from their checking account.

h. Your mother told me that you saved/save your coupons in a special coupon wallet.

i. Grandmother always sewed/sews your buttons on with heavy-duty thread.

j. Have the passengers sailed in the boat/ship yet, or is it still being repaired at the dock?

The same speaker from Experiment 2 read each version of the sentences for recording, producing palatalization at the key site for the versions in which the key word ended in $/ d /$ or $/ t /$. Another phonetician listened to the productions and confirmed that the key word pairs were palatalized in the appropriate version. The target words were then deleted and replaced by silence using the computerized editing procedure described previously. For the nonpalatalized version of each sentence, the entire target word was deleted. For the palatalized version, however, only the portion of the key word preceding the palatal affricate was deleted and replaced with silence.

In this case, the boundary between the affricate and the preceding vowel was defined to be the point of plosive release for the affricate. Once again, an interactive listening procedure was used to help identify this phoneme boundary on the waveform display and to delete the portion of the word that preceded it.

Listeners were tested using the same procedure as in previous experiments. The subjects were divided into two groups of 24 , with each group hearing one version of each sentence and an equal number of palatalized and nonpalatalized versions.

\section{Results and Discussion}

The results are presented in Table 3 . The responses were categorized both in terms of words that are compatible with palatalization (i.e., words ending in $/ d /, / t /$, $/ \mathrm{j} /$, or $/ \bar{c} /$ ) and in terms of matches with one of the two target words. An analysis of variance revealed that the palatalized version of the test sentences elicited a greater number of responses ending in $/ \mathrm{d} /, / \mathrm{t} /, / \mathrm{j} /$, or $/ \overline{\mathrm{c}} /$ than the nonpalatalized version $[F(1,47)=4.703, p<.05]$. 
Table 3

Number of Responses by Reconstruction Type in Experiment 3

\begin{tabular}{lcccc}
\hline & \multicolumn{3}{c}{ Sentence Version } \\
\cline { 2 - 5 } & Palatalized & $\%^{*}$ & Nonpalatalized & $\%^{*}$ \\
\hline Responses ending in $/ \mathrm{d} /, / \mathrm{t} /, / \mathrm{j} /$, or $/ \overline{\mathrm{c}} /$ & 116 & 48.3 & 96 & 40.0 \\
Palatalizable target word & 90 & 37.5 & 70 & 29.2 \\
Nonpalatalizable target word & 81 & 33.7 & 108 & 45.0 \\
\hline
\end{tabular}

*Percentage of the total number of responses.

In addition, as shown in Table 3, more palatalizable target words were elicited with the palatalized sentence versions than with the nonpalatalized versions.

Comparison of the results for Experiments 2 and 3 suggests that the influence of palatalization on word reconstruction is more pronounced for lexical selection involving palatalization at the beginnings of words than for that involving palatalization at the ends of words. This finding is in agreement with earlier work on speech production of palatalization (Cooper, Egido, \& Paccia, 1978), showing that palatalization at the beginnings of words is far more susceptible to blocking by factors such as emphatic stress and low word frequency than is palatalization at the ends of words. The finding is also consistent with data showing that listeners are more sensitive to information contained at the beginnings (as opposed to the ends) of words in detecting mispronunciations (Cole, Jakimik, \& Cooper, 1978) and in lexical selection for speech generally (e.g., Marslen-Wilson \& Welch, 1978; Salasoo \& Pisoni, 1985).

\section{EXPERIMENT 4}

In this experiment, we sought to determine whether listeners' sensitivity to acoustic cues would be extended to a cue for which the acoustic information does not directly convey accompanying articulatory information from the speaker. In particular, we wanted to determine whether the duration of the silent interval that had replaced the missing word would influence listeners' restorations. If listeners utilize durational cues in their restorations, relatively short silent intervals should be accompanied by short-word restorations, whereas relatively long silent intervals should be accompanied by long-word restorations, ceteris paribus.

\section{Method}

Subjects. Seventy-four University of Iowa undergraduates, none of whom had participated in earlier word reconstruction tests, served in this experiment. The subjects had the same qualifications as those who had served in previous experiments.

Sentence materials. Ten sentences were constructed for use in this experiment. Each sentence included an optional word choice in which the two options differed substantially in their typical spoken durations. The surrounding context was designed to heavily constrain word choice at the key location so that choice of words other than the two options specified would be minimized, while each of the two intended choices would be nearly equiprobable. In each case below, the two intended choices were approximately equal in their general frequency of usage in English
(Kučera \& Francis, 1967). Pilot work was conducted on a larger list of candidate sentences to arrive at a set of sentences that met each of these requirements as nearly optimally as English permits. The 10 sentences appear below:

11. a. Many people feel that they are just nameless/anonymous faces when they are on a crowded city sidewalk.

b. My mother thought our dinner guest was very rude/impolite because he burped loudly and complained about the food.

c. The children in the public grade/elementary school went out onto the playground for recess.

d. Some people feel that watching too much violence on tv/television is unhealthy for children.

e. The burglar was arrested by a cop/policeman shortly after the crime was committed.

f. Janice rides her bike/bicycle to work every morning in order to stay in shape.

g. The scientist was in her lab/laboratory conducting an experiment.

h. Going to the dance will give you a good chance/opportunity to meet new people.

i. The woman joined that particular club/organization in order to participate in charity projects for the community.

j. The woman read a book/magazine while sitting in the doctor's waiting room.

Procedure. In preparing the stimulus tape, the trained speaker from Experiment 2 read each of the 10 sentences in two versions, including each of the two optional key words in separate readings. The computerized editing procedure described in Experiment 2 was then utilized to replace the key word of each string with a silent interval of equal duration. The average key-word duration for the short versions of the sentences was $408 \mathrm{msec}$; the average key word duration for the long versions was $607 \mathrm{msec}$. Although the difference in number of syllables between matched long and short versions was sometimes as great as $5: 1$, the difference in duration is not as marked in speech because polysyllabic words are typically spoken with compressed unstressed syllables (see, e.g., Klatt, 1976).

Three groups of 19 subjects and one group of 17 subjects were tested using the procedure described in Experiment 1. Each group heard five sentences, including either two or three long silent-interval versions coupled with either three or two short silent-interval versions. No group heard both versions of any one sentence. The test sentences were intermixed with 30 fillers in a pseudorandomized order that was comparable for each group.

\section{Results and Discussion}

The main results are presented in Table 4. A Pearson product correlation relating the duration of the silent interval with the corresponding number of syllables in the response was computed across sentences for each subject. Individual values were transformed to $Z$, using Fisher's transformation, and then averaged (Lindeman, Merenda, \& Gold, 1980, pp. 53-54). This analysis revealed that the duration of the silent interval was significantly correlated 
Table 4

Number of Target Word Responses and Mean Number of Syllables in Response Words for Experiment 4

\begin{tabular}{lcccc}
\hline & \multicolumn{4}{c}{ Sentence Version } \\
\cline { 2 - 5 } & Short & $\% *$ & Long & $\% *$ \\
\hline Short target word & 86 & 45.3 & 58 & 30.5 \\
Long target word & 65 & 34.2 & 84 & 44.2 \\
Mean** & 2.4 & \multicolumn{2}{c}{2.7} \\
SD & 1.54 & & \multicolumn{2}{c}{1.6} \\
\hline *Percentage of the total number of responses. & & $* *$ Mean number of \\
syllables in response. & &
\end{tabular}

with the number of syllables in the response $(r=.376$, $\mathrm{z}=4.8163, \mathrm{p}<.001$ ), although this relationship accounted for only $14 \%$ of the variance $\left(r^{2}=.14\right)$.

These results indicate that listeners do take into account the duration of the silent interval corresponding to a missing word when choosing a lexical item to fill this location. However, the fact that the duration of the silent interval accounted for a relatively small percentage of the variance in the number of syllables of the listeners' reconstructions suggests that this acoustic factor might play a minor role in ordinary listening, in which word choice is not limited to approximately two candidates. To explore this notion preliminarily, we asked 48 new listeners to reconstruct a missing word in the single string "John planted beans and (corn/cauliflower) in his garden last summer." This string was selected because its context restricted the missing word to the domain of vegetables but still allowed for numerous choices with wide variation in numbers of syllables. In this test, listeners were presented one of two versions of the string, either one originally spoken with "corn" as the target word or one originally spoken with "cauliflower." The word durations of the two targets was 419 and $790 \mathrm{msec}$, respectively. These words were replaced by silent intervals of equivalent durations, as in the main experiment. In this circumstance, listeners showed no tendency to replace the shorter silent interval with a word containing fewer syllables than the longer silent interval. The mean number of syllables in the listeners' responses was $1.50(\mathrm{SD}=$ $.764)$ for the "corn" version and $1.54(\mathrm{SD}=.763)$ for the "cauliflower" version.

We then asked whether or not the durational cue would become more salient if the target words were replaced with real-world noise, yielding a filled rather than empty test interval (see, e.g., Fraisse, 1963). Accordingly, we replaced the two target words (i.e., "corn," and "cauliflower") with a chair-scrape noise of corresponding duration. The recording of a naturally produced chair scrape was edited to the appropriate durations by deleting the medial segment, thereby maintaining the natural acoustic onset and offset of the noise. Each sentence was presented to a different group of 19 subjects. Listeners again showed no tendency to replace the shorter noise interval with a word containing fewer syllables than the longer noise interval. The mean number of syllables in the listeners' responses was $1.74(\mathrm{SD}=.784)$ for the "corn" version and $1.84(\mathrm{SD}=.987)$ for the "cauliflower" version. On the basis of these follow-up tests, it appears that the impact of the duration cue on ordinary listening reconstruction is minimal, although more systematic testing with a wider range of materials is clearly needed on this point.

\section{GENERAL DISCUSSION}

The results of Experiments 1-4 indicate that listeners can make use of detailed acoustic information in attempting to decide whether a word is missing from the speech signal (Experiment 1) and, if so, to guide in lexical selection of the reconstructed word (Experiments 2, 3, and 4). These findings distinguish the present work from earlier studies with the cloze procedure (see, e.g., Taylor, 1953), in which semantic and syntactic cues to word reconstruction were examined, typically in reading rather than in speech perception.

The results of Experiments 2 and 3 also reveal that listeners possess implicit knowledge of the operation of a subtle and complex cross-word phonological conditioning rule, namely palatalization. While our listeners possessed no explicit knowledge of this rule, which converts a $/ t /$ or $/ d /$ to $/ \mathrm{j} /$ in the environment of a following $/ y /$, their selection of reconstructed words was significantly influenced by the presence of palatalization cues at the key site.

The fact that listeners can utilize a word-initial $/ \bar{j} /$ or $/ \bar{c} /$ to guide lexical reconstruction of words that ordinarily start with $/ y /$ indicates that phonetically atypical information at the beginning of a word can be properly transformed by coarticulatory rules back to its typical form prior to lexical access. This capacity might well be limited to listeners who regularly utilize such coarticulatory rules in their speech production (see Scott \& Cutler, 1984). In addition, it will be interesting to determine whether this capacity is applicable to ordinary on-line word recognition. If so, some current theories of on-line word recognition would need to be modified to incorporate this capacity. For example, the cohort theory (e.g., MarslenWilson \& Tyler, 1980; Marslen-Wilson \& Welsh, 1978; Tyler, 1984) would need to be modified to include this type of processing operation at a stage that precedes the formulation of an initial cohort.

The fact that listeners are influenced by the acoustical fine structure of the speech signal suggests, though by no means proves, that the reconstruction process itself might be accomplished quickly, probably before the end of the sentence. Otherwise, the results would indicate that listeners can store relatively subtle acoustical properties for a longer time than indicated by earlier work on precategorical acoustical storage (see, e.g., Crowder \& Morton, 1969). Further work is needed on the detailed time course of the reconstruction process to examine these possibilities.

Although our focus in this study has involved word reconstruction, it is likely that, in many ordinary listening 
circumstances, listeners do not attempt precise lexical reconstruction at all, even when the site of a missing word is detected, but, rather, try to formulate gist solely on the basis of the other words present. For example, a listener could derive a general meaning for the string "The (missing word) gave me her sandwich" without actually reconstructing the missing word (although, in some contexts, the derived meaning would still be deficient in important respects from the intended message, as when a specific female noun was intended). Alternatively, in this circumstance, reconstruction might involve the listener's replacing the missing word with a representation like a semantic feature bundle that includes most, but not all, features of the target word (e.g., + noun, +animate, +female). In other cases, the listeners might not detect a missing word, incorrectly interpret a string, and then update the interpretation on the basis of subsequent sentences without actually reconstructing the missed word or even being aware of its location. For example, if a string-initial "no" is missed in the string " (No) buses are running on Tuesday," the gist of this sentence might be inappropriately decoded as affirmative and then corrected upon successful decoding of a following sentence, such as "Thus, we won't be going to Sue's tomorrow.' 'If the listener did not originally detect the location of the missed word, it would be difficult or impossible to reconstruct the word precisely. In this case, the negative could alternatively have appeared as "not" before "running." Moreover, it is at least conceivable that the listener does not retain a verbatim memory for the message long enough to locate the missing-word site. It thus seems likely that in such instances listeners do not restore specific lexical items to specific locations but, rather, update the gist as more information is decoded. In still other cases, a listener might request that the speaker repeat all or part of the message (e.g., "What?"; Valian \& Wales, 1976) when a missed word or other anomalous aspect of the original utterance is detected, rather than attempt reconstruction.

In ordinary settings, missing information is often unexpected, unlike the contexts examined here, and we have begun to examine the extent to which listeners accomplish reconstruction in such instances (e.g., Cooper, TyeMurray, \& Nelson, 1985). Such work has involved including, at most, a single deletion per paragraph context, with foil paragraphs containing other speech abnormalities, and asking listeners comprehension questions that critically depend on the reconstruction site rather than asking them to restore words per se. These measures permit an examination of whether the reconstruction process drains information-processing capacity during ordinary listening and the consequences for comprehension. The results indicate that the comprehension of material immediately following the reconstruction site is selectively impaired. Thus, word reconstruction is not accomplished without cost, and work can now be directed at specifying the nature of this cost in more realistic circumstances, involving acoustic masking and momentary diverting of at- tention during extended listening. In addition, it will be important in future work to deal with more realistic domains of missing information. In real-world circumstances, a listener more routinely misses portions of speech that do not correspond exactly to individual word segments.

\section{REFERENCES}

Cole, R. A., JAkImIK, J., \& Cooper, W. E. (1978). Perceptibility of phonetic features in fluenct speech. Journal of the Acoustical Society of America, 64, 44-56.

Cooper, W. E., Eady, S. J., \& Mueller, P. M. (1985). Acoustical aspects of contrastive stress in question-answer contexts. Journal of the Acoustical Society of America, 77, 2142-2156.

Cooper, W. E., Egido, C. , \& PACCIA, J. M. (1978). Grammatical control of a phonological rule: Palatalization. Journal of Experimental Psychology: Human Perception \& Performance, 4, 264-272.

COOPER, W. E., \& Sorensen, J. (1981). Fundamental frequency in sentence production. New York: Springer.

CoOper, W. E., Tye-Murray, N., \& Nelson, L. (1985). Missing words and comprehension of spoken text. Manuscript submitted for publication.

Crowder, R. G., \& Morton, J. (1969). Precategorical acoustic storage (PAS). Perception \& Psychophysics, 5, 365-373.

Cutler, A. (1976). Phoneme-monitoring reaction time as a function of preceding intonation contour. Perception \& Psychophysics, 20, 55-60.

FraISSE, P. (1963). The psychology of time. New York: Harper \& Row. Johnson, M. K., \& RAYE, C. L. (1981). Reality monitoring. Psychological Review, 88, 67-85.

KLATT, D. H. (1976). Linguistic uses of segmental duration in English. Journal of the Acoustical Society of America, 59, 1208-1221.

KuČERA, F., \& FRANCIs, W. (1967). Computational analysis of presentday American English. Providence, RI: Brown University Press.

LIEBERMAN, P. (1967). Intonation, perception, and language. Cambridge, MA: MIT Press.

Lindeman, R. H., Merenda, P. F., Gold, R. Z. (1980). Introduction to bivariate and multivariate analysis. Glenview, IL: Scott, Foresman.

MAEDA, S. (1976). A characterization of American English intonation. Unpublished PhD dissertation, Massachusetts Institute of Technology.

MARSLEN-Wilson, W. D., \& TYLER, L. K. (1980). The temporal structure of spoken language understanding. Cognition, 8, 1-71.

Marslen-Wilson, W. D., \& Welsh, A. (1978). Processing interactions and lexical access during word recognition in continuous speech. Cognitive Psychology, 10, 29-63.

Martin, J. G. (1972). Rhythmic (hierarchical) versus serial structure in speech and other behavior. Psychological Review, 6, 487-507.

MORTON, J., \& LONG, J. (1976). Effect of word transitional probability on phoneme identification. Journal of Verbal Learning \& Verbal Be. havior, 15, 43-51.

Oshika, B. T., Zue, V. W., WeEks, R. V., NeU, H., Aurbach, J. (1975). The role of phonological rules in speech understanding research. IEEE Transactions on Acoustics, Speech \& Signal Processing, 23, 104-112.

Salasoo, A., \& Pisoni, D. B. (1985). Interaction of knowledge sources in spoken word identification. Journal of Verbal Learning \& Verbal Behavior, 24, 210-231.

SAmUel, A. G. (1981a). Phonemic restoration: Insights from a new methodology. Journal of Experimental Psychology: General, 110, 474-494.

SAMUE L, A. G. (1981b). The role of bottom-up confirmation in the phonemic restoration illusion. Journal of Experimental Psychology: Human Perception \& Performance, 7, 1124-1131.

ScotT, D. R., \& Cutler, A. (1984). Segmental phonology and the perception of syntactic structure. Journal of Verbal Learning \& Verbal Behavior, 23, 450-466. 
Stanovich, K. E., \& West, R. F. (1981). The effect of sentence context on ongoing word recognition: Tests of a two-process theory. Journal of Experimental Psychology: Human Perception \& Performance, 7, 658-672.

TAYLOR, J. A. (1953). Cloze procedure: A new tool for measuring readability. Journalism Quarterly, 30, 424-433.

TYLER, L. K. (1984). The structure of the initial Cohort: Evidence from gating. Perception \& Psychophysics, 36, 417-427.
VAIssiére, J. (1980). The search for language-independent prosodic features. Paper presented at the International Congress on the Perception of Speech, Florence, Italy.

VALIAN, V., \& WALES, R. (1976). What's what: Talkers help listeners hear and understand by clarifying sentential relations. Cognition, 4 , 155-176.

WARREN, R. M. (1970). Perceptual restoration of missing speech sounds. Science, 167, 392-393.

(Manuscript received March 29, 1985;

revision accepted for publication July 22,1985 .) 